\title{
Correction of coronal plane deformities around knee in children with two-hole tension band plates
}

\author{
Erdi Özdemir, MD®D, Abdülsamet Emet, MD®, Rafik Ramazanov, MD®D, Güney Yılmaz, MD® \\ Department of Orthopedics and Traumatology, Hacettepe University Faculty of Medicine, Ankara, Turkey
}

A coronal plane deformity around knee is a common problem encountered in pediatric population. These angular deformities can be idiopathic in origin, or they can emerge secondary to congenital and acquired abnormalities. ${ }^{[1]}$ Persistent coronal plane deformities around knee (genu varum/valgum) could lead to meniscal tears, collateral ligament laxity, cartilage degeneration, and early osteoarthritis due to gradual mechanical axis disruption..$^{[2-4]}$

There are several treatment modalities defined in the literature for the coronal deformities around knee in pediatric population. In the previous literature, corrective osteotomies are the commonly used technique to treat these deformities. However, in the recent literature, hemiepiphysiodesis (guided growth) has become one of the most common surgical procedures alternative to the corrective osteotomies in coronal plane deformities around the knee encountered in pediatric population. ${ }^{[5]}$

Received: September 10, 2020

Accepted: October 16, 2020

Published online: January 06, 2021

Correspondence: Güney Yılmaz, MD. Hacettepe Üniversitesi Tıp Fakültesi Ortopedi ve Travmatoloji Anabilim Dalı, 06100 Sıhhiye Ankara, Türkiye.

E-mail: aflguney@hotmail.com

\section{Doi: 10.5606/ehc.2021.78879}

Citation: Özdemir E, Emet A, Ramazanov R, Yılmaz G. Correction of coronal plane deformities around knee in children with twohole tension band plates. Jt Dis Relat Surg 2021;32(1):177-184.

(02021 All right reserved by the Turkish Joint Diseases Foundation

This is an open access article under the terms of the Creative Commons Attribution-NonCommercial License, which permits use, distribution and reproduction in any medium, provided the original work is properly cited and is not used for commercial purposes (http://creativecommons.org/licenses/by-nc/4.0/).

\section{ABSTRACT}

Objectives: This study aims to present the 10 -year results and complications of two-hole tension band plate hemiepiphysiodesis for coronal deformities around knee in a large population from a single center.

Patients and methods: Seventy-seven patients (46 boys, 31 girls; mean age $93 \pm 36$ months; range, 22 to 181 months) who underwent temporary hemiepiphysiodesis around knee between January 2009 and January 2019 with two-hole tension band plates were retrospectively evaluated. Improvement of joint orientation angles and mechanical axis deviations, deformity correction rates, etiology groups, and complications were noted.

Results: A total of 166 bone segments (93 femurs, 73 tibias) were included in the study. Mean follow-up duration after the implantation was $36 \pm 17$ (range, 12 to 88 ) months. Plates were removed at mean $18 \pm 8$ (range, 7 to 47 ) months of implantation. Of the bone segments, 95.2\% $(n=158)$ responded successfully to the plates. Mean correction rate of mechanical lateral distal femoral angle in femoral valgum deformity was $0.94 \pm 0.43^{\circ}$ (range, 0.17 to 2.22)/month and mean correction rate of mechanical medial proximal tibial angle in tibial valgum deformity was $0.62 \pm 0.36^{\circ}$ (range, 0.11 to 1.55 ) $/$ month. Mean correction rate of mechanical lateral distal femoral angle in femoral varum deformity was $1.3 \pm 0.8^{\circ}$ (range, 0.48 to 2.92 )/month and mean correction rate of mechanical medial proximal tibial angle in tibial varum deformity was $0.94 \pm 0.49^{\circ}$ (range, 0.26 to 1.67 )/month. The most common complication observed was rebound deformity seen in $41.2 \%(n=70)$ of the bone segments. Nine bone segments had persistent hemiepiphysiodesis despite plate removal. Four screw breakages (three metaphysial and one epiphysial) were observed.

Conclusion: Two-hole tension band plate hemiepiphysiodesis appears to be an effective and safe method for the correction of coronal deformities around knee.

Keywords: Complication, coronal plane deformity, guided growth, hemiepiphysiodesis, tension band plate.

The technique which is used for hemiepiphysiodesis/guided growth relies on the restrictive effect of the surgical procedure on the cellular activity of the growth plate as described by Hueter-Volkmann principle. Different types of guided growth techniques have gained popularity 
due to low complication rates. Guided growth can be accomplished by permanent way as described by Phemister. ${ }^{[6]}$ However, precise timing is mandatory in permanent technique thus it can result in over/under corrections. The second option in the light of the current literature is temporary guided growth. It utilizes different types of implants, is technically easier, and the growth plate activity resumes once the implant is removed..$^{[7]}$ Temporary guided growth can be accomplished with a staple, transphyseal screw or a two-hole tension band plate. The literature comprises good outcomes for staples in terms of deformity correction. ${ }^{[8]}$ On the other hand, complications including pull-out of the staple, migration, breakage, and premature physeal closure were also reported..$^{[9]}$ Correction with percutaneous epiphysiodesis with transphyseal screws (PETS), which was introduced by Métaizeau et al., ${ }^{[10]}$ is also effective although the risk of permanent physeal closure was reported in studies. ${ }^{[11]}$

Two-hole plate mediated guided growth working as a tension band was described by Stevens ${ }^{[12]}$ and this guided growth technique with two-hole tension band plates for correction of coronal plane deformities of knee has been widely accepted by pediatric orthopedic surgeons. ${ }^{[13]}$ However, studies with large populations with longer follow-up are still missing in the literature. In this study, we aimed to present the ten-year results and complications of two-hole tension band plate hemiepiphysiodesis for coronal deformities around knee in a large population from a single center.

\section{PATIENTS AND METHODS}

We retrospectively reviewed patients who were treated with guided growth utilizing two-hole tension band plating (Orthofix Medical Inc., Lewisville, TX, USA and TST Medical Devices, Istanbul, Turkey) between January 2009 and January 2019 in Department of Orthopedics and Traumatology of Hacettepe University Faculty of Medicine. A total of 209 bone segments (113 femurs, 96 tibias) of 98 children (61 boys, 37 girls) were analyzed. Patients treated for lower extremity coronal plane deformities (genu varum/ valgum) who had regular full-length lower extremity weight-bearing radiographs, treated with two-hole tension band plate, and completed the treatment were included in the study. 166 bone segments ( 93 femurs, 73 tibias) of 77 patients ( 46 boys, 31 girls; mean age $93 \pm 36$ months; range, 22 to 181 months) met the inclusion criteria. The study protocol was approved by the Hacettepe University Faculty of Medicine Ethics Committee (GO 20/687). A written informed consent was obtained from the legal guardian of each patient. The study was conducted in accordance with the principles of the Declaration of Helsinki.

Deformity analysis of the patients was performed pre- and postoperatively based on the full-length lower extremity weight-bearing radiographs with mechanical lateral distal femoral angle (mLDFA), mechanical medial proximal tibial angle (mMPTA), and mechanical axis deviation (MAD). Anatomic locations where the two-hole tension band plates were applied were decided based on joint orientation angles including $\mathrm{MMPTA}, \mathrm{mLDFA}$, and MAD measured as the distance in $\mathrm{mm}$ between the center of the knee and the mechanical axis line. Mechanical axis deviation values were given in genu varum bone segments as negative values and in genu valgum segments as positive values. Mechanical axis deviation evaluation was not used in patients who had a history of osteotomy. Surgical procedures were performed with previously described techniques by two pediatric orthopedic fellowship-trained surgeons as follows. ${ }^{[12]}$ The location where the plate would be applied was determined under fluoroscopic guidance. A $3 \mathrm{~cm}$ incision was performed on the sagittal plane centered on the physis and the bone was exposed without harming the periosteum. Then, the physis was marked with a needle to determine the optimal place for the plate. Following the fluoroscopic confirmation of the optimal plate placement on both anteroposterior and lateral planes, epiphysial and metaphysial screws were inserted. Patients were allowed to be weight bearing as tolerated immediately after surgery and they were followed-up regularly at four-month intervals until the desired correction was achieved. The plates were removed once the deformity was corrected (Figure 1 and 2). Deformity analysis was performed with full-length lower extremity weight-bearing radiographs in each control visit. Correction rate in mLDFA and mMPTA was calculated in degrees per month and MAD in millimeters per month based on preoperative and final measurements.

The deformity correction rates in joint orientation angles of the patients were analyzed based on etiology groups (Table I). Mechanical axis deviation correction rate was compared in patients treated for only femur, only tibia, or both femur and tibia. A subgroup analysis was performed on patients who had a prolonged treatment period ( $>24$ months) with two-hole tension band plate. Complications were noted during the follow-ups.

\section{Statistical analysis}

Statistical analysis was performed
using the IBM SPSS version 23.0 software


(IBM Corp., Armonk, NY, USA). Descriptive statistics were expressed as mean \pm standard deviation for continuous numerical variables, while categorical variables were expressed as the number of patients and percentage. Distribution of variables was measured with the Kolmogorov-Smirnov test. Statistical analysis was performed with paired sample t-test, Student t-test, and analysis of variance with posthoc Tukey test to compare mean values. The results were considered statistically significant when the $p$ value was $<0.05$.

\section{RESULTS}

A total of 140 bone segments had genu valgum and 26 bone segments had genu varum deformity. Mean follow-up duration after the implantation was $36 \pm 17$ (range, 12 to 88 ) months. Plates were removed at mean $18 \pm 8$ (range, 7 to 47 ) months of implantation. Of the bone segments, 95.2\% $(n=158)$ responded successfully to the plates and were corrected to normal alignment or slightly overcorrected.

Patients were evaluated separately in genu valgum and genu varum deformity groups. Mean age at surgery was $99 \pm 38$ (range, 37 to 181) months in genu valgum group and $71 \pm 34$ (range, 22 to 118) months in genu varum group. Mean follow-up duration in genu valgum and varum groups was $36 \pm 18$ (range, 12 to 88 ) months and $36 \pm 11$ (range, 18 to 54 ) months, respectively. Significant improvement at joint orientation angles and MAD distances was observed in both genu varum and genu

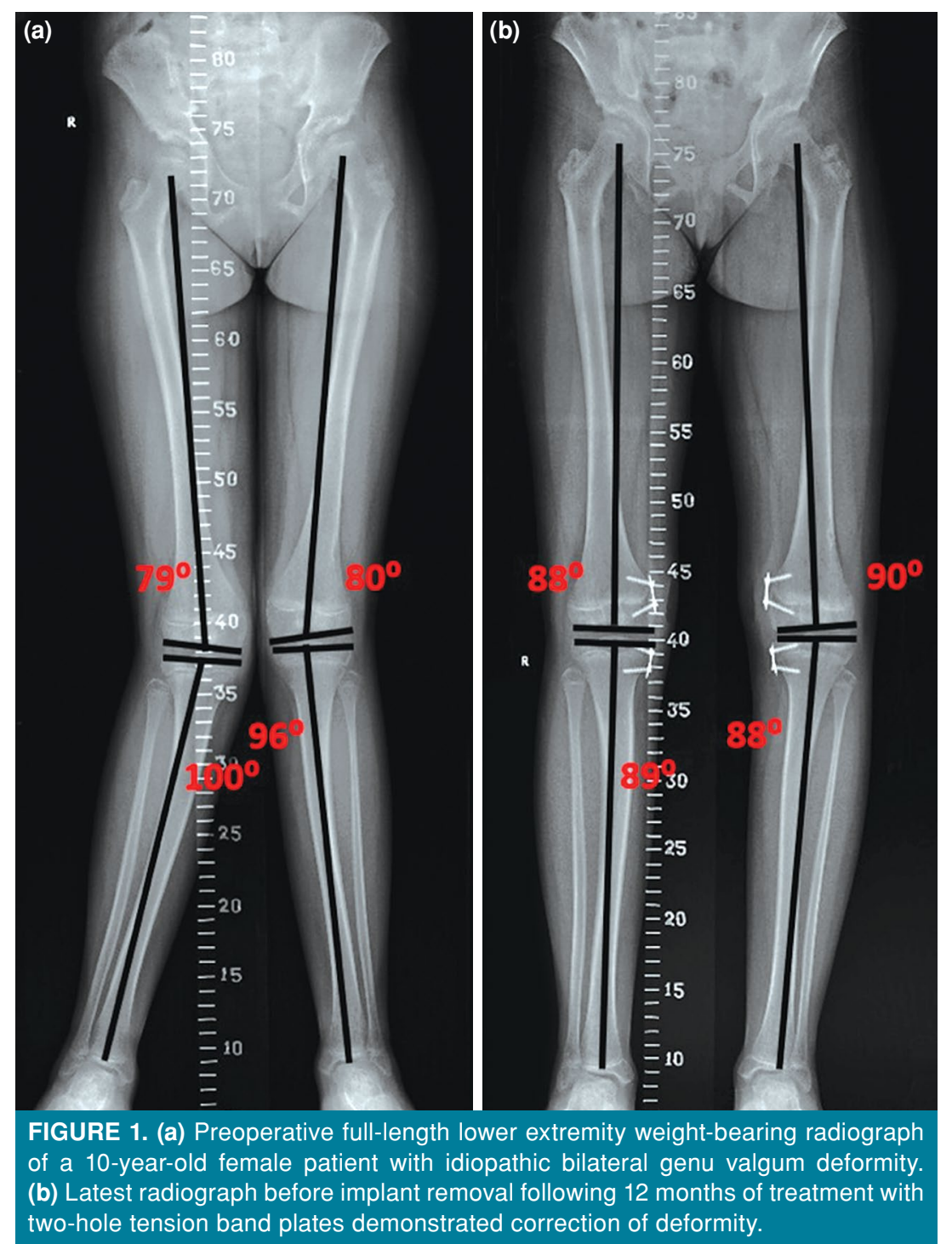


valgum patients (Table II). Mean correction rate of mLDFA in femoral valgum and varum deformity was $0.94 \pm 0.43^{\circ}$ (range, 0.17 to 2.22 )/ month and $1.3 \pm 0.8^{\circ}$ (range, 0.48 to 2.92 )/month, respectively. Mean correction rate of mMPTA in tibial valgum and varum deformity was $0.62 \pm 0.36^{\circ}$ (range, 0.11 to 1.55$) /$ month and $0.94 \pm 0.49^{\circ}$ (range, 0.26 to 1.67 )/month, respectively.

Deformity correction rates of joint orientation angles were measured based on etiology groups. Mean mLDFA correction rate was $1.01 \pm 0.37^{\circ}$ (range, 0.50 to 1.89$) /$ month in idiopathic group $(\mathrm{n}=23)$, $1.14 \pm 0.64^{\circ}$ (range, 0.22 to 2.33 )/month in dysplastic group ( $n=18), 0.95 \pm 0.43^{\circ}$ (range, 0.22 to 1.81 )/month in endocrine-metabolic disease group $(n=20), 1.12 \pm 0.60^{\circ}$ (range, 0.17 to 2.92$) /$ month in congenital group $(\mathrm{n}=19)$, and $0.83 \pm 0.57^{\circ}$ (range, 0.21 to 2.22$) /$ month $(n=13)$ in acquired group $(\mathrm{p}=0.530)$. Mean mMPTA correction ratewas $0.75 \pm 0.32^{\circ}$ (range, 0.12 to 1.27 )/monthinidiopathic group ( $\mathrm{n}=14$ ), $0.84 \pm 0.58^{\circ}$ (range, 0.11 to 1.67$) /$ month in dysplastic group $(\mathrm{n}=13), 0.58 \pm 0.27^{\circ}$ (range, 0.20 to $1.08) /$ month in endocrine-metabolic disease group $(\mathrm{n}=14), 0.64 \pm 0.47^{\circ}$ (range, 0.12 to 1.38 ) $/$ month in congenital group $(n=13), 0.63 \pm 0.22^{\circ}$ (range, 0.48 to $0.89) /$ month in Blount's disease group $(\mathrm{n}=8)$, and $0.62 \pm 0.35^{\circ}$ (range, 0.15 to 1.55 )/month in acquired group $(\mathrm{n}=11)(\mathrm{p}=0.582)$.

Mean correction rate of MAD was 2.1 \pm 1.7 (range, 0.10 to 7.63 ) $\mathrm{mm} /$ month in bone segments only treated for femoral deformity $(n=46)$ and $1.8 \pm 1.1$
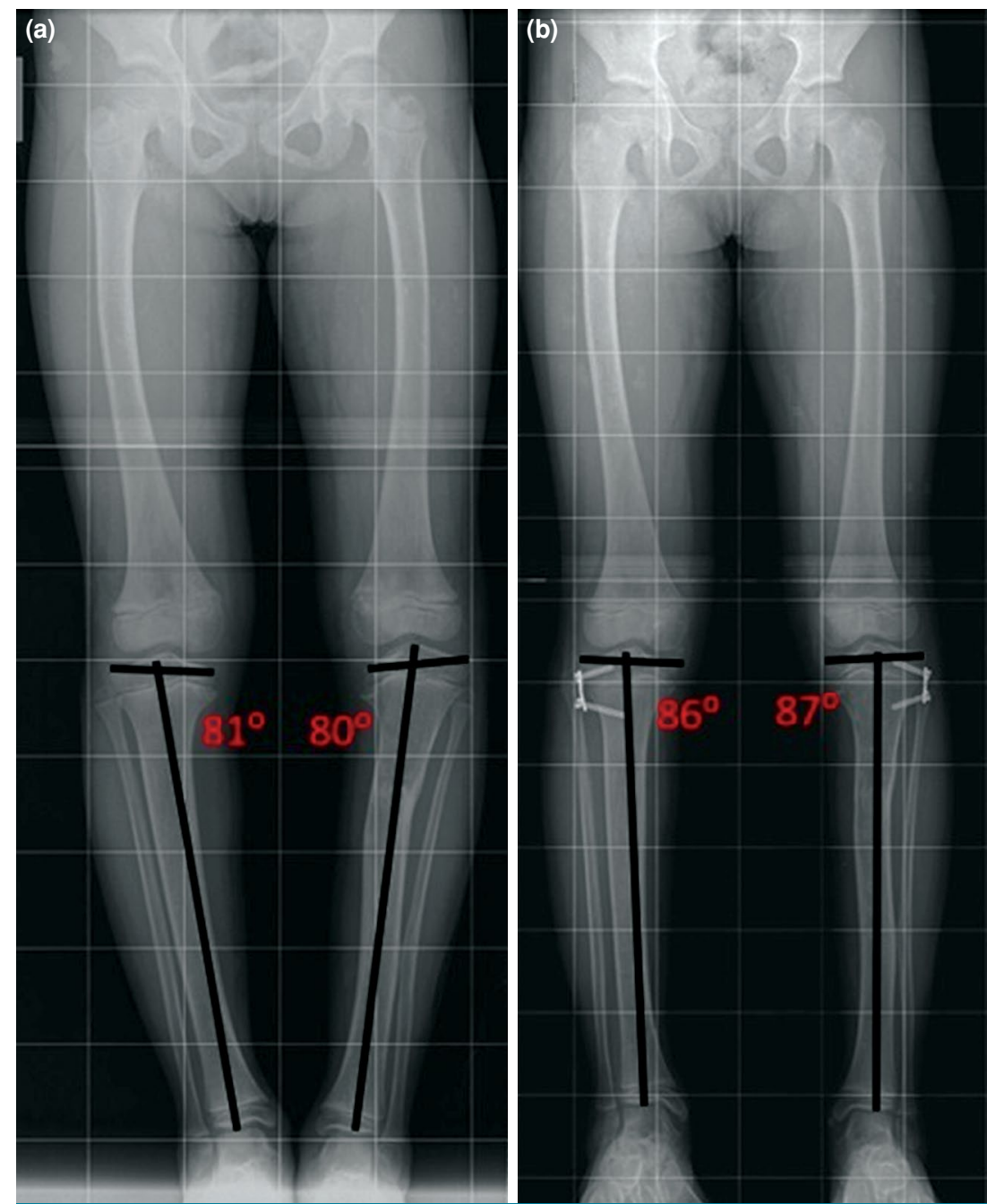

FIGURE 2. (a) Preoperative full-length lower extremity weight-bearing radiograph of a seven-year-old female patient with bilateral genu varum deformity due to Blount's disease. (b) Deformity was corrected in 23 months with two-hole tension band plate treatment. 


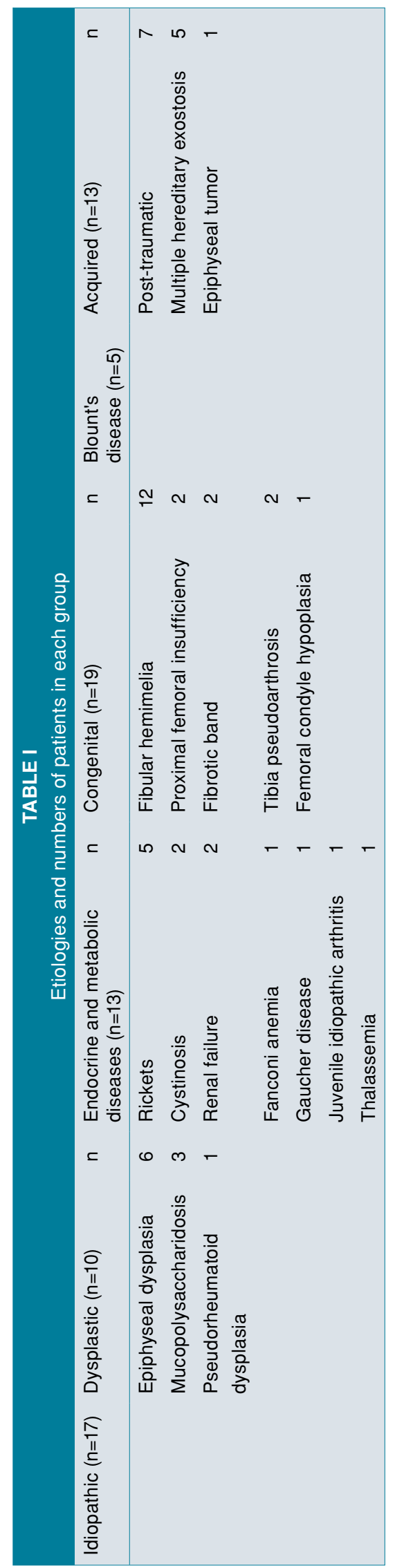

\begin{tabular}{|c|c|c|c|}
\hline \multicolumn{4}{|c|}{$\begin{array}{c}\text { TABLE II } \\
\text { Pre- and postoperative mechanical lateral distal femoral } \\
\text { angle, medial proximal tibial angle, and mechanical } \\
\text { axis deviation distance measurements in genu varum } \\
\text { ( } \mathrm{n}=26 \text { bone segments) and valgum } \\
(\mathrm{n}=140 \text { bone segments) patients }\end{array}$} \\
\hline & Preoperative & Postoperative & \\
\hline & Mean $\pm S D$ & Mean $\pm S D$ & $p$ \\
\hline \multicolumn{4}{|l|}{ mLDFA } \\
\hline Genu varum & $106 \pm 9.5^{\circ}$ & $87.5 \pm 5.0^{\circ}$ & $<0.001^{*}$ \\
\hline $\begin{array}{l}\text { Genu valgum } \\
\text { mMPTA }\end{array}$ & $79.5 \pm 4.2^{\circ}$ & $93.3 \pm 5.1^{\circ}$ & $<0.001^{*}$ \\
\hline Genu varum & $79.6 \pm 5.3^{\circ}$ & $93.4 \pm 4.0^{\circ}$ & $<0.001^{*}$ \\
\hline Genu valgum & $98.3 \pm 6.8^{\circ}$ & $88.6 \pm 8.5^{\circ}$ & $<0.001^{*}$ \\
\hline \multicolumn{4}{|l|}{ MAD } \\
\hline Genu varum & $-33 \pm 12.3 \mathrm{~mm}$ & $10.7 \pm 6.2 \mathrm{~mm}$ & $<0.001^{*}$ \\
\hline Genu valgum & $32 \pm 15 \mathrm{~mm}$ & $-7 \pm 14 \mathrm{~mm}$ & $<0.001^{*}$ \\
\hline
\end{tabular}

SD: Standard deviation; mLDFA: Mechanical lateral distal femoral angle; mMPTA: Medial proximal tibial angle; MAD: Mechanical axis deviation.

(range, 0.14 to 4.58$) \mathrm{mm} /$ month in bone segments only treated for tibial deformity $(\mathrm{n}=25)$. Bone segments treated for both tibial and femoral deformities $(\mathrm{n}=82)$ on the ipsilateral extremity had mean $3.2 \pm 1.2$ (range, 0.20 to 6.00 ) $\mathrm{mm} /$ month correction in the MAD which was higher compared to the isolated femur and tibial deformities $(\mathrm{p}<0.001, \mathrm{p}<0.001)$.

Bone segments with prolonged treatment period (15 femurs, 12 tibias) were analyzed as a subgroup. At the annual follow-up, mean mLDFA correction rate of prolonged treatment group $\left(0.52 \pm 0.27^{\circ}\right.$ [range, 0.17 to $0.92 /$ month versus $1.1 \pm 0.52^{\circ}$ [range, 0.21 to 2.92 ] $/$ month, $\mathrm{p}<0.001$ ) and mean mMPTA correction rate $\left(0.44 \pm 0.40^{\circ}\right.$ [range, 0.11 to 1.21 ] $/$ month versus $0.73 \pm 0.41^{\circ}$ [range, 0.15 to 1.67 ] $/$ month, $\mathrm{p}=0.033$ ) were slower than the non-prolonged group. One valgus femur and one valgus tibia in the prolonged treatment group had persistent hemiepiphysiodesis effect after implant removal.

The most common complication observed was the rebound of the deformity seen in 70 bone segments $(41.2 \%)$. We assumed a change in joint orientation angles $5^{\circ}$ and above after implant removal as rebound deformity. In genu valgum deformity group, $40(50.6 \%)$ femurs and $23(37.7 \%)$ tibias had rebound deformity. In genu varum deformity group, two (7\%) femurs and five (19\%) tibias had rebound deformity. Two-hole tension band plates were re-implanted to rebounded four femurs and five tibias of the genu valgum groups. 
Seven of the tibias including two fibular hemimelias, two rickets, one tibial pseudoarthrosis, one epiphyseal dysplasia, one post-traumatic, and one femur with femoral condyle hypoplasia who did not respond to the two-hole tension band plates in genu valgum group were treated with a corrective osteotomy (4.8\%). The hemiepiphysiodesis effect persisted in five tibias (two valgus, three varus) and four femurs (two valgus, two varus) despite plate removal. The overall infection rate was $0.9 \%$ (two plates). Four screws (three metaphyseal and one epiphyseal) of three plates were broken. No plate breakage was observed.

\section{DISCUSSION}

In the current study, we present 95.2\% ( $\mathrm{n}=158)$ correction of coronal deformities around the knee in a pediatric population with two-hole tension band plates operated in a single center through a ten-year period..$^{[14,15]}$ Only $4.8 \%(n=8)$ of the patients required corrective osteotomies.

Before the clinical application of hemiepiphysiodesis techniques, corrective osteotomies were the preferred method of treatment of coronal plane deformities around knee in pediatric population. Mycoskie ${ }^{[16]}$ reported $63 \%$ complication rate after corrective osteotomy including loss of alignment, vascular complications, pathologic fractures, wound infection, anterior and posterior angulation at the osteotomy site, tibial tubercle prominence, and patellofemoral malalignment. In the current study, only eight patients (4.8\%) underwent a corrective osteotomy for deformity correction despite treatment with two-hole tension band plates and $95.2 \%$ of the patients avoided corrective osteotomies. Use of two-hole tension band plates may reduce osteotomy requirement in coronal plane deformity correction in children and osteotomy related complications.

The definition of success in the treatment of coronal plane deformities around knee has been commonly made based on the requirement of the corrective osteotomy. Stevens ${ }^{[12]}$ reported that 63 of $65(97 \%)$ deformities were treated with guided growth, preventing corrective osteotomies. Burghardt and Herzenberg ${ }^{[17]}$ demonstrated treatment success in 50 of 54 bone segments (90\%) with use of tension band plates. We successfully treated 158 of 166 bone segments (95.2\%) with two-hole tension band plate hemiepiphysiodesis. The results of the current study were consistent with the previous literature. ${ }^{[12,17]}$
Many previous studies have reported the overall correction rates for mLDFA, MMPTA, and MAD without grouping according to etiologies utilizing two-hole tension band plating. ${ }^{[17-19]}$ Danino et al. ${ }^{[19]}$ reported the results of a multinational study including 967 bone segments of 537 patients with different etiologies who were treated with two-hole tension band plates. They had a mean $0.77^{\circ}$ month correction rate for mLDFA and $0.79^{\circ}$ month correction rate for mMPTA. Burghardt and Herzenberg ${ }^{[17]}$ demonstrated a mean $0.65^{\circ}$ (range, 0.05 to 1.67 ) month correction rate for mLDFA and $0.58^{\circ}$ (range, 0.13 to 1.67 ) month correction rate for mMPTA. The authors also stated that they had overall 1.73 (range, 0 to 6.4 ) $\mathrm{mm} / \mathrm{month}$ correction of MAD. We had mean $0.94 \pm 0.43^{\circ}$ (range, 0.17 to 2.22 )/month correction rate for mLDFA and $0.62 \pm 0.36^{\circ}$ (range, 0.11 to 1.55 )/month correction rate for mMPTA in genu valgum group and had $1.3 \pm 0.8^{\circ}$ (range, 0.48 to 2.92 ) $/$ month correction rate for mLDFA and $0.94 \pm 0.49^{\circ}$ (range, 0.26 to 1.67 )/ month correction rate for mMPTA in genu varum group. We evaluated the change in MAD based on operated bone segments. Our mean correction rate of MAD was $2.1 \pm 1.7$ (range, 0.10 to 7.63 ) $\mathrm{mm} /$ month in bone segments only treated for femoral deformity $(\mathrm{n}=46), 1.8 \pm 1.1$ (range, 0.14 to 4.58$) \mathrm{mm} / \mathrm{month}$ in bone segments only treated for tibial deformity $(\mathrm{n}=25)$, and $3.2 \pm 1.2$ (range, 0.20 to 6.00$) \mathrm{mm} / \mathrm{month}$ for bone segments treated for both tibial and femoral deformities $(n=82)$. The overall correction rates for mLDFA, mMPTA, and MAD were consistent with the literature. ${ }^{[17-19]}$ As expected, mean correction rate of MAD was higher when both segments were operated on the ipsilateral extremity. In contrast to the results of Danino et al. ${ }^{[19]}$ and Burghardt and Herzenberg ${ }^{[17]}$ regarding overall deformity correction rates with heterogeneous etiologies, Guzman et al. ${ }^{[20]}$ reported a mean $0.32^{\circ} /$ month deformity correction rate in mLDFA in a homogenous patient population including only idiopathic genu valgum patients. Mielke and Steven $s^{[8]}$ stated that idiopathic bone segments have faster correction rate compared to bone segments with pathological growth plates. We had similar correction rate on joint orientation angles according to different etiology groups (idiopathic, dysplastic, endocrine-metabolic, congenital, Blount's disease, acquired). Although our aim in grouping the etiologies was to evaluate the patients in a more homogenous way, different etiologies in the same groups in the current study may have led to inconsistent results with the literature. Further research with more homogenous groups would be beneficial. 
Patients treated with guided growth for coronal plane deformities around knee are commonly followed-up with full-length lower extremity weight-bearing radiographs in every three to six months. ${ }^{[12,18]}$ However, some patients have slower correction rates hence they may be exposed to higher radiation doses due to the full-length lower extremity weight-bearing radiographs obtained in every three to six months. ${ }^{[21]}$ We evaluated patients who had a prolonged treatment period ( $>24$ months). Patients in the prolonged treatment group had slower deformity correction rate (mean mLDFA correction rate was $0.52 \pm 0.27^{\circ}$ [range, 0.17 to 0.92 ] / month, mean mMPTA correction rate was $0.44 \pm 0.40^{\circ}$ [range, 0.11 to 1.21 ] $/$ month) in their annual follow-up compared to the non-prolonged treatment group (mean mLDFA was $1.1 \pm 0.52^{\circ}$ [range, 0.21 to 2.92 ] / month, mean mMPTA correction rate was $0.73 \pm 0.41^{\circ}$ [range, 0.15 to 1.67 ] $/$ month). Considering the radiation exposure in the prolonged treatment group, patients who had a mean correction rate for mLDFA under $0.5^{\circ}$ month and for mMPTA under $0.4 \%$ month in the annual follow-up may be followed-up with wider periods than four months or could be evaluated with regular anteroposterior knee radiographs.

Staple hemiepiphysiodesis has been one of the options for the correction of coronal deformities around knee since it was first described by Blount. $^{[22]}$ Some serious complications such as implant breakage and physeal arrest have been reported in the previous literature. ${ }^{[23]}$ In addition, PETS has been an alternative technique for temporary epiphysiodesis. It provides minimally invasive surgery; however, has permanent arrest risk of the growth plates. ${ }^{[1]}$ Removal of staples and transphyseal screws within two years after implantation is recommended to avoid permanent physeal arrest. ${ }^{[11,12]}$ According to our results, two-hole tension band plate hemiepiphysiodesis can be continued for over two years until the achievement of target correction. However, we observed permanent hemiepiphysiodesis effect after implant removal of two bone segments (one valgus femur, one valgus tibia) in the prolonged treatment group ( $>24$ months). In addition, a total of five tibias (two valgus, three varus) and four femurs (two valgus, two varus) had hemiepiphysiodesis effect despite plate removal. Adhesions, small bone bridges or physeal damage during plate insertion or removal may cause the hemiepiphysiodesis effect after implant removal. It can be concluded that two-hole tension band plate hemiepiphysiodesis may also cause growth arrest as staple or PETS hemiepiphysiodesis.

Rebound growth of the deformity seems to be the main problem of the two-hole tension band plate hemiepiphysiodesis. Zajonz et al. ${ }^{[18]}$ reported a 3.8\% rebound rate and Stevens ${ }^{[12]}$ reported a $12.8 \%$ rebound rate; however, the quantitative measurement of rebound growth in these studies has not been clearly defined. In the current study, we assumed the rebound phenomenon as a change in mLDFA and mMPTA $5^{\circ}$ and above. We reported $41.2 \%$ rebound rate after implant removal. Since rebound growth was not the topic of the current study, we believe further studies defining the rebound growth after two-hole tension band plate hemiepiphysiodesis and investigating the underlying risk factors would be beneficial.

Since two-hole tension band plates offer dynamic construct in contrast to staples which provide a rigid construct over its length, implant breakage can still present in patients' follow-ups. ${ }^{[23]}$ Danino et al. ${ }^{[19]}$ reported $0.53 \%$ screw breakage rate in their large series and stated that all of the broken screws were metaphysial. Burghardt et al. ${ }^{[24]}$ investigated the mechanical failures of two-hole tension band plates and reported that mechanical failures almost always occur at metaphysial screws. None of the plates were broken in our patients but we observed 1.4\% $(n=4)$ screw breakage rate (three metaphysial and one epiphysial).

Its retrospective design and absence of a control group are the major limitations of our study. Body mass index values of the patients were not available in the current study which may have affected the results. Since these deformities may be caused by some rare disorders, we have presented the results of a diverse population. Further controlled studies with more homogenous groups would be enlightening.

In conclusion, two-hole tension band plate hemiepiphysiodesis appears to be an effective and safe method for the correction of coronal deformities around knee.

\section{Declaration of conflicting interests}

The authors declared no conflicts of interest with respect to the authorship and/or publication of this article.

\section{Funding}

The authors received no financial support for the research and/or authorship of this article.

\section{REFERENCES}

1. Boero S, Michelis MB, Riganti S. Use of the eight-Plate for angular correction of knee deformities due to idiopathic 
and pathologic physis: initiating treatment according to etiology. J Child Orthop 2011;5:209-16.

2. Metcalf MH, Barrett GR. Prospective evaluation of 1485 meniscal tear patterns in patients with stable knees. Am J Sports Med 2004;32:675-80.

3. van Lieshout WAM, Martijn CD, van Ginneken BTJ, van Heerwaarden RJ. Medial collateral ligament laxity in valgus knee deformity before and after medial closing wedge high tibial osteotomy measured with instrumented laxity measurements and patient reported outcome. J Exp Orthop 2018;5:49.

4. Tanamas S, Hanna FS, Cicuttini FM, Wluka AE, Berry P, Urquhart DM. Does knee malalignment increase the risk of development and progression of knee osteoarthritis? A systematic review. Arthritis Rheum 2009;61:459-67.

5. Goldman V, Green DW. Advances in growth plate modulation for lower extremity malalignment (knock knees and bow legs). Curr Opin Pediatr 2010;22:47-53.

6. Phemister, DB. Operative Arrestment of longitudinal growth of bones in the treatment of deformities. JBJS 1933;15:1-15.

7. Stevens PM. Guided growth: 1933 to the present. Strategies Trauma Limb Reconstr 2006;1:29-35.

8. Mielke $\mathrm{CH}$, Stevens PM. Hemiepiphyseal stapling for knee deformities in children younger than 10 years: a preliminary report. J Pediatr Orthop 1996;16:423-9.

9. Raab P, Wild A, Seller K, Krauspe R. Correction of length discrepancies and angular deformities of the leg by Blount's epiphyseal stapling. Eur J Pediatr 2001;160:668-74.

10. Métaizeau JP, Wong-Chung J, Bertrand H, Pasquier P. Percutaneous epiphysiodesis using transphyseal screws (PETS). J Pediatr Orthop 1998;18:363-9.

11. Shin SJ, Cho TJ, Park MS, Bae JY, Yoo WJ, Chung CY, et al. Angular deformity correction by asymmetrical physeal suppression in growing children: stapling versus percutaneous transphyseal screw. J Pediatr Orthop 2010;30:588-93.

12. Stevens PM. Guided growth for angular correction: a preliminary series using a tension band plate. J Pediatr Orthop 2007;27:253-9.
13. El-Sobky TA, Samir S, Baraka MM, Fayyad TA, Mahran MA, Aly AS, et al. Growth Modulation for Knee Coronal Plane Deformities in Children With Nutritional Rickets: A Prospective Series With Treatment Algorithm. J Am Acad Orthop Surg Glob Res Rev 2020;4:e19.00009.

14. Atik OŞ. Is there something new and interesting in my article? Eklem Hastalik Cerrahisi 2019;30:69.

15. Atik OŞ. What are the expectations of an editor from a scientific article? Jt Dis Relat Surg 2020;31:597-8.

16. Mycoskie PJ. Complications of osteotomies about the knee in children. Orthopedics 1981;4:1005-15.

17. Burghardt RD, Herzenberg JE. Temporary hemiepiphysiodesis with the eight-Plate for angular deformities: mid-term results. J Orthop Sci 2010;15:699-704.

18. Zajonz D, Schumann E, Wojan M, Kübler FB, Josten C, Bühligen $U$, et al. Treatment of genu valgum in children by means of temporary hemiepiphysiodesis using eightplates: short-term findings. BMC Musculoskelet Disord 2017;18:456.

19. Danino B, Rödl R, Herzenberg JE, Shabtai L, Grill F, Narayanan U, et al. Guided growth: preliminary results of a multinational study of 967 physes in 537 patients. J Child Orthop 2018;12:91-6.

20. Guzman H, Yaszay B, Scott VP, Bastrom TP, Mubarak SJ. Early experience with medial femoral tension band plating in idiopathic genu valgum. J Child Orthop 2011;5:11-7.

21. Zampogna B, Vasta S, Amendola A, Uribe-Echevarria Marbach B, Gao Y, Papalia R, et al. Assessing lower limb alignment: comparison of standard knee $X$ ray vs long leg view. Iowa Orthop J 2015;35:49-54.

22. Blount WP, Clarke GR. Control of bone growth by epiphyseal stapling; a preliminary report. J Bone Joint Surg [Am] 1949;31:464-78.

23. Kumar A, Gaba S, Sud A, Mandlecha P, Goel L, Nayak M. Comparative study between staples and eight plate in the management of coronal plane deformities of the knee in skeletally immature children. J Child Orthop 2016;10:429-37.

24. Burghardt RD, Specht SC, Herzenberg JE. Mechanical failures of eight-plateguided growth system for temporary hemiepiphysiodesis. J Pediatr Orthop 2010;30:594-7. 